\title{
Volatiles emitted from the roots of Vetiveria zizanioides suppress the decline in attention during a visual display terminal task
}

\author{
Eri Matsubara ${ }^{1}$, Kuniyoshi Shimizu ${ }^{1}$, Mio Fukagawa ${ }^{1}$, Yuka Ishizi ${ }^{1}$, Chikako Kakol ${ }^{2}$, Tomoko Hatayama ${ }^{3}$, \\ Jun Nagano ${ }^{4}$, Tsuyoshi OKamoto ${ }^{5}$, Koichiro Ohnuki ${ }^{2}$, and Ryuichiro Kondo ${ }^{1}$ \\ ${ }^{1}$ Department of Agro-environmental Sciences, Faculty of Agriculture, Kyushu University, 6-10-1 Hakozaki, Higashi-ku, Fukuoka \\ 812-8581, Japan; ${ }^{2}$ Faculty of Food and Nutrition, Kyushu Nutrition Welfare University, 5-1-1 Shimoitozu, Kokurakita-ku, Kitakyushu- \\ shi, Fukuoka 803-8511, Japan; ${ }^{3}$ Department of Psychology and Human Relations, Faculty of Humanities, Nanzan University, 18 \\ Yamazato-cho, Showa-ku, Nagoya, Aichi 466-8673, Japan; ${ }^{4}$ Institute of Health Science, Kyushu University, 6-1 Kasuga Park, Kasuga, \\ Fukuoka 816-8580, Japan; and ${ }^{5}$ Graduate School of Medical Sciences, Kyushu University, 3-1-1 Maidashi, Higashi-ku, Fukuoka \\ 812-8582, Japan
}

(Received 13 July 2012; and accepted 21 August 2012)

\begin{abstract}
The perennial grass Vetiveria zizanioides (vetiver) is mainly cultivated for its fragrant essential oil. Although the components of the oil and their biological activities have been studied extensively, the effect of the volatiles emitted from the roots of $V$. zizanioides on humans has so far remained unexplored. We investigated the effects of volatile compounds emitted from the cut roots of $V . z i$ zanioides ( $1.0 \mathrm{~g}$, low-dose conditions; $30 \mathrm{~g}$, high-dose conditions) on individuals during a visual display terminal task. Participants who breathed the volatile compounds emitted under low-dose conditions showed faster reaction times and stimulation of sympathetic nerve activity as measured by electrocardiography. These effects were not observed under high-dose conditions. The total amount of volatiles emitted during the experiment was $0.25 \mu \mathrm{g}$ under low-dose conditions and $1.35 \mu \mathrm{g}$ under high-dose conditions. These findings indicate that volatile compounds emitted from the roots of $V$. zizanioides under low-dose conditions may have helped subjects to maintain performance in visual discrimination tasks while maintaining high sympathetic nerve system activity.
\end{abstract}

The perennial grass Vetiveria zizanioides is widely cultivated, especially in Southeast Asia. The roots of V. zizanioides (Fig. 1) contain many volatile compounds; the essential oil, collected by steam distillation of the roots, is a viscous liquid that varies in color from amber to dark brown $(4,26)$, and in general, its odor is described as earthy and woody (2). Because of its excellent fixative properties, $V$. zizanioides is one of the most important raw materials in perfumery $(16,23)$. The authors of most of the previous studies of $V$. zizanioides have aimed to identify the compounds of the essential oil prepared

Address correspondence to: Dr Kuniyoshi Shimizu, Department of Agro-environmental Sciences, Faculty of Agriculture, Kyushu University, 6-10-1 Hakozaki, Higashi-ku, Fukuoka 812-8581, Japan

E-mail: shimizu@agr.kyushu-u.ac.jp from the roots of $V$. zizanioides and elucidate the activities of this essential oil $(3,5,8,11,15,18,35)$. The qualities of the essential oil prepared from the roots of $V$. zizanioides depend on genetic, environmental and technological factors $(17,25)$. Although the roots of $V$. zizanioides have been used as described above since ancient times, and impressions of the volatiles of the roots were different from those of the essential oil, the effects of the volatiles directly emitted from the roots of $V$. zizanioides have not been explored.

We previously established an experimental method to evaluate the effects of aromatic herbs in relation to the performance of a visual discrimination task (19-22). Aromatic herbs act through olfactory pathways in the brain, including the cerebral cortex, hypothalamus and amygdala, which are different from the visual transduction and processing path- 


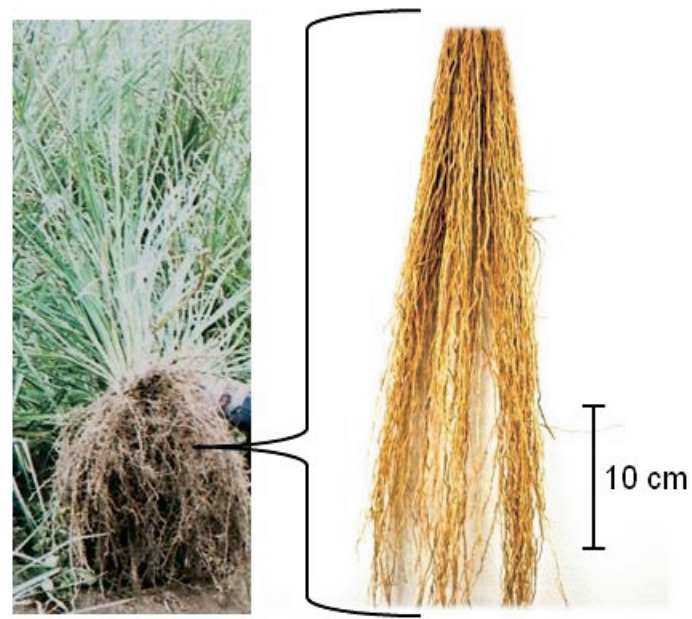

Fig. 1 Roots of Vetiveria zizanoides.

ways (27). It was previously reported that experiences of odor and hedonic valence, as well as feelings of pleasure and displeasure, influence cognitive and behavioral responses $(6,12,32)$, and we suggested in a previous report that the odorants related to positive emotion have the potential to maintain performance during a visual discrimination task (20). Our preliminary study indicated a difference in the perception of the odor between the essential oil and the roots of $V$. zizanioides; the odor of the roots was perceived as light and refreshing, while that of the essential oil was not. These preliminary results led us to focus on the volatiles directly emitted from the roots of $V$. zizanioides.

We report that breathing the volatiles emitted from the roots of $V$. zizanioides improves performance in a visual discrimination task. We present our investigation of the associated temporary changes of sympathetic nerve activity as measured by electrocardiography (ECG), and we discuss the mode of action of the volatiles on task performance.

\section{MATERIALS AND METHODS}

Materials and chemicals. The dried roots of V. zizanioides (Fig. 1) and the essential oil of $V$. zizanioides were provided by Akaru Corp. (Kurume, Japan). $\beta$-Caryophyllene was purchased from Tokyo Chemical Industry Co. (Tokyo, Japan). High-purity acetone was purchased from Wako Pure Chemical Industries, Ltd. (Acetone 300, Osaka, Japan).

Qualitative and quantitative analysis of volatile compounds. The volatiles emitted from the roots of $V$. zizanioides were analyzed by a gas chromatograph- mass spectrometer (GC-MS) (GC-17A-QP5050; Shimadzu Co., Ltd., Kyoto, Japan) equipped with a DB-5 column $(30 \mathrm{~m} \times 0.25 \mathrm{~mm}$ i.d., $0.25 \mu \mathrm{m}$ film thickness; Agilent Technologies Japan Ltd., Tokyo, Japan) and with both solid-phase microextraction (SPME) fiber coated with a $65-\mu \mathrm{m}$-thick layer of PDMS/DVB (Supelco, Bellefonte, PA, USA) and a Curie-point pyrolyzer (Japan Analytical Industry Co., Ltd., Tokyo, Japan). The Curie-point pyrolyzer was used to desorb the volatiles absorbed in the absorbent.

SPME fiber was used for qualitative analysis. The fiber was conditioned before use as recommended by the manufacturer (at $250^{\circ} \mathrm{C}$ for $30 \mathrm{~min}$ ). The roots of $V$. zizanioides were cut into $1.0-\mathrm{cm}$ lengths, and the assays were carried out at $20 \pm 2{ }^{\circ} \mathrm{C}$ by placing $1.0 \mathrm{~g}$ of the root in a sealed $50-\mathrm{mL}$ glass vial for $30 \mathrm{~min}$. The headspace volatiles were evaluated using the fiber with a 15-min extraction from the root. The fiber was then retracted and immediately inserted into the injector port of the GC-MS. The temperature program of the GC-MS was as follows: $80^{\circ} \mathrm{C}$ for $3 \mathrm{~min}$ followed by increases of $10^{\circ} \mathrm{C} \mathrm{min}^{-1}$ up to $100^{\circ} \mathrm{C}$, then increases of $3^{\circ} \mathrm{C} \min ^{-1}$ up to $200^{\circ} \mathrm{C}$ and then increases of $10^{\circ} \mathrm{C} \mathrm{min}{ }^{-1}$ up to $250^{\circ} \mathrm{C}$. The temperature was then held for $10 \mathrm{~min}$. The other parameters were as follows: injection temperature, $250^{\circ} \mathrm{C}$; ion source temperature, $250^{\circ} \mathrm{C}$; ionization energy, $70 \mathrm{eV}$; carrier gas, $\mathrm{He}$ at $1.7 \mathrm{~mL}$ $\min ^{-1}$; mass range, $\mathrm{m} / \mathrm{z} 50$ to 450 . Mass spectral database libraries (1) were used for substance identification.

We have analyzed and calculated the quantitative values of the volatiles that were presented to the participants with the same odorant delivery system used in our experiment. The roots of $V$. zizanioides were cut into $1.0-\mathrm{cm}$ lengths, and we adjusted the weight of the roots to be either $1.0 \mathrm{~g}$ or $30 \mathrm{~g}$. The cut roots were placed in a glass chamber, and air was put into this chamber at a constant rate of $1.0 \mathrm{~L}$ $\min ^{-1}$ controlled by a constant-flow olfactometer. The volatiles from the roots of $V$. zizanioides were collected in a Tedlar PVF bag for $40 \mathrm{~min}$, and then we added $5 \mu \mathrm{L}$ of linalool/acetone $(10 \mu \mathrm{L} / \mathrm{mL})$ to the Tedlar PVF bag as an internal standard for quantitative analysis and left the bag at room temperature for $30 \mathrm{~min}$. The volatiles and internal standard in the Tedlar PVF bag were transferred to a Tenax GR adsorbent $(25 \mathrm{mg})$ in quartz glass by using a suction pump. The volatiles and internal standard were transferred at $20 \pm 2{ }^{\circ} \mathrm{C}$ using a flow rate of $0.05 \mathrm{~L} \mathrm{~min}^{-1}$ for $15 \mathrm{~h}$. The volatiles absorbed in the Tenax GR were desorbed immediately at $280^{\circ} \mathrm{C}$ in 
a Curie-point pyrolyzer (Japan Analytical Industry Co., Ltd., Tokyo, Japan) and then subjected to GCMS analysis. The volatiles from the roots of $V$. zizanioides are not commercially available; therefore, the standard line for quantitative analysis was taken as the area of the $\beta$-caryophyllene peak, and the concentrations of the target compounds in the sample were calculated by using the calibration standard line of $\beta$-caryophyllene. The analysis was repeated five times, and the average \pm SD was calculated.

Odorant delivery. The volatiles were delivered for
40 min using odorless air (Table 1). The roots of $V$. zizanioides were cut into $1.0-\mathrm{cm}$ lengths; the weight of each sample was either $1.0 \mathrm{~g}$ (low-dose conditions) or $30 \mathrm{~g}$ (high-dose conditions). The odorant delivery system (illustrated in Fig. 2, (19-22)) was controlled by a constant-flow olfactometer that forced air at a constant rate of $1.0 \mathrm{~L} \mathrm{~min}^{-1}$ through Teflon tubing into a charcoal trap. The air was then put in a 300-mL glass chamber (Sansyo, Tokyo, Japan) with or without the $V$. zizanioides roots. The experiment room $(1.3 \times 1.8 \times 2.0 \mathrm{~m}$; Avitecs, Yamaha Corp., Shizuoka, Japan) was maintained at $22 \pm 2^{\circ} \mathrm{C}$ during

Table 1 Time schedule

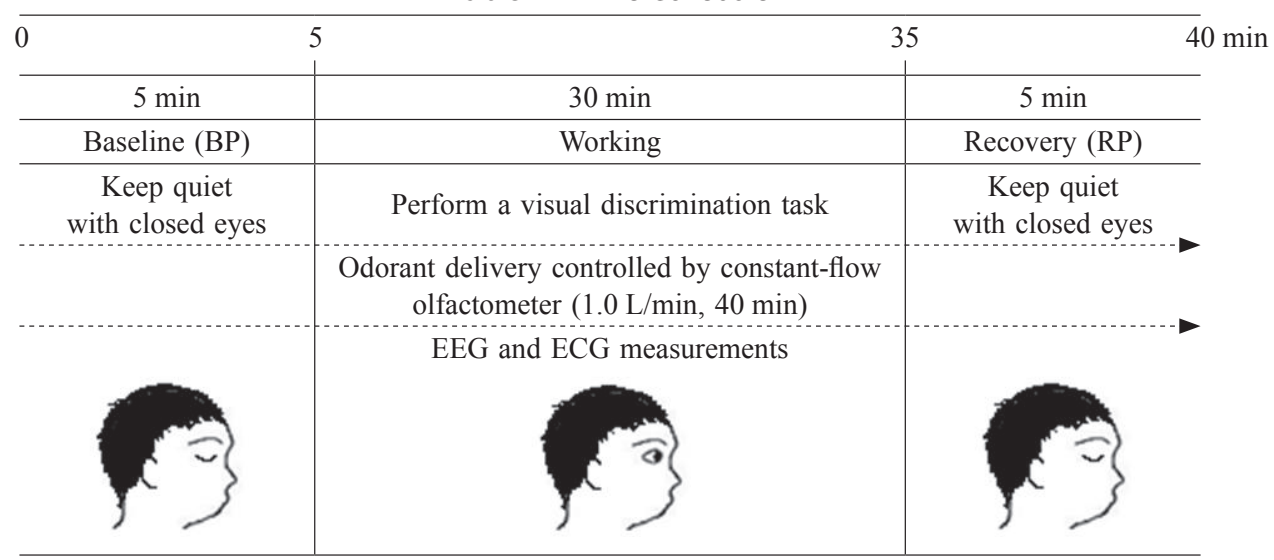

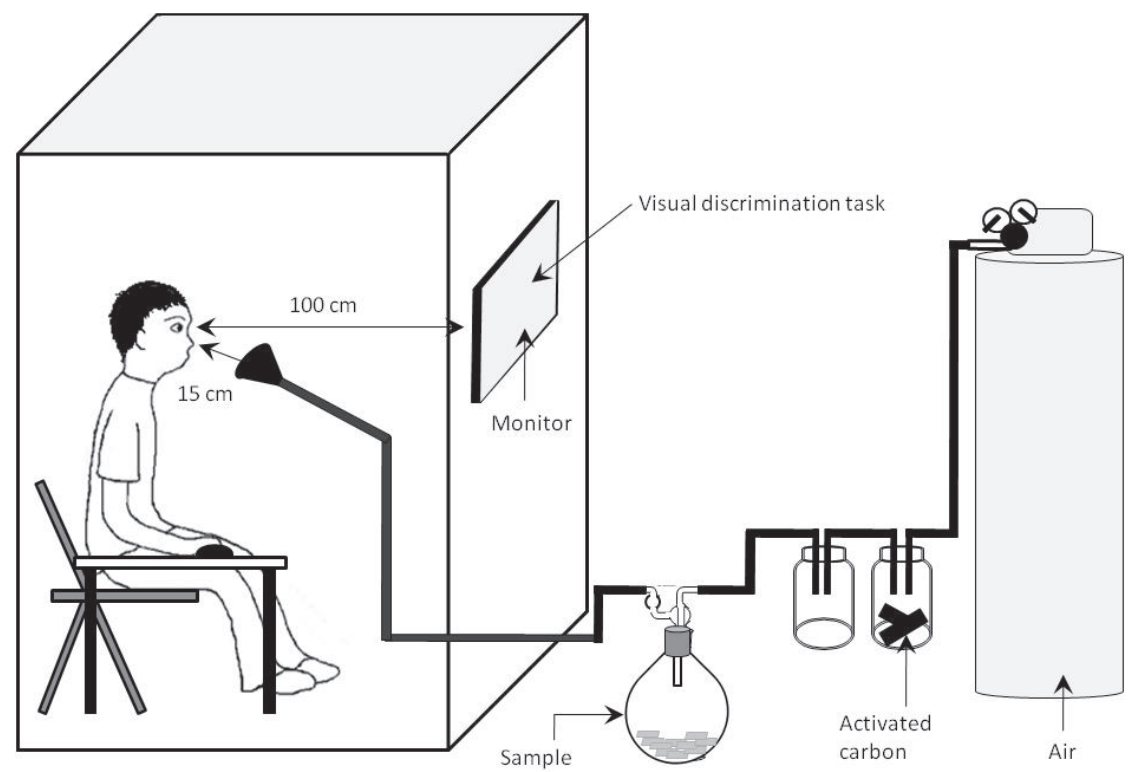

Fig. 2 Schematic diagram of the experimental configuration. The visual discrimination task (VDT) and olfactory system. The odorant delivery system was regulated by a constant-flow olfactometer, which forced air at a constant flow rate of $1.0 \mathrm{~L} /$ min. Air from the chamber with or without the $V$. zizanioides roots was transmitted to a modified mask immobilized $15 \mathrm{~cm}$ from the nose of a participant. Each participant was seated in front of a VDT monitor at a viewing distance of approximately $100 \mathrm{~cm}$. 
all of the experiments. Each experiment was performed over the same period of time. Air with or without the volatiles was given from the baseline period to the recovery period (Table 1).

Participants. The experimental design of the study was approved by Kyushu University and was in accordance with the Declaration of Helsinki. Eighteen healthy university students $(10$ men and 8 women, age 20 to $28 \mathrm{y}$ ) were recruited for the study. Six participants performed the experiment twice: once with no odor and once under low-dose conditions at an interval of 1 week. Twelve participants performed the experiment twice: once with no odor and once under high-dose conditions at an interval of 1 week. During the study, none of the participants had abnormalities in their sense of smell, suffered physical or mental health problems, used drugs or smoked. The order of conditions was randomized in this study. The purpose and schedule of the experiments were explained, and written informed consent for study participation was obtained from all participants prior to beginning the study. Before the experiment, participants were instructed to sleep sufficiently, to avoid excessive exercise on the day and night before the experiment, and not to arrive fatigued or drowsy on the day of the experiment. Consumption of alcohol or medication one day before the experiment, and consumption of caffeine on the day of the experiment were prohibited. Participants were not informed which odor was applied and whether they were being subjected to the odor or odorless conditions throughout the experimental period.

Visual discrimination task. The visual discrimination task was performed for a 30-min working period that started $5 \mathrm{~min}$ after the experimental time began and ended $5 \mathrm{~min}$ before the experimental period ended (Table 1). Participants were tested individually in a $1.3 \times 1.8 \times 2.0 \mathrm{~m}$ industrial acoustics sound room (Avitecs) that was fully sealed from ambient noise and light. During the test, participants were seated in front of a 21.3-inch color LCD monitor (RDT214S, $1600 \times 1200$ pixels, $300 \mathrm{~cd} / \mathrm{m}^{2}$; Mitsubishi Electric Corp., Tokyo, Japan) controlled by a computer (Windows XP). The viewing distance was approximately $100 \mathrm{~cm}$. A 30-min visual discrimination task performed on a visual display terminal (VDT) was previously reported by Matsubara et al. (2009). A series of random numbers between 0 and 9 appeared on the screen, and each number was presented for $40 \mathrm{~ms} \mathrm{~s}^{-1}$. Static random noise was displayed in the outer frame of the screen at a $1.4 \times 1.3^{\circ}$ diameter viewing angle. The noise was increased for each number to increase the difficulty of the task. The series of numbers was presented at a $0.91 \times 0.68^{\circ}$ diameter viewing angle. Participants were asked to click the mouse when ' 0 ' appeared but not to click the mouse when other numbers appeared. Vigilance performance was calculated by two indices: [1] the reaction time, defined as the time taken to click when the correct targets appeared; and [2] the rate of true hits, $\mathrm{p}(\mathrm{tH})$, defined as the rate of correct responses minus the rate of incorrect responses.

ECG recording. The ECG trace was recorded using $\mathrm{Ag} / \mathrm{AgCl}$-electrodes (LecTrode NP; Advance Co. Ltd., Tokyo, Japan) placed in the CM5 position. To evaluate cardiac autonomic nervous activity, we performed a power spectral analysis of R-R intervals using a MemCalc system (MemCalc Ver. 2.5; Suwa Trust Co., Tokyo, Japan). Heart rate variability (HRV) was assessed by a two-dimensional Lorenz scatter plot of the successive interval versus the immediately preceding R-R interval (31). ECG recordings were played back from a two-channel recorder, and the signals were digitized using a 12-bit analogue-to-digital converter at a sampling rate of $1 \mathrm{kHz}$. The low-frequency (LF, 0.04-0.15 Hz) and high-frequency $(\mathrm{HF}, 0.15-0.4 \mathrm{~Hz}$ ) components were analyzed. Changes in the mean R-R intervals, the HF components and $\mathrm{LF} / \mathrm{HF}$ ratios were calculated as percentage changes compared with the unstipulated periods before the baseline (absence of the roots).

Statistical analysis. In all experiments, statistical analysis was performed using a paired Student's t-test to compare the difference between conditions at 5 -min intervals. The values are expressed as mean \pm SEM. $P$ values less than 0.05 were considered significant, and $P$ values less than 0.1 were considered to indicate a tendency. All statistical analysis was performed using SPSS 15.0J for Windows (SPSS Japan, Tokyo, Japan).

\section{RESULTS}

The effects of the volatile compounds emitted from the roots of $V$. zizanioides on performance of a visual discrimination task and on ECG traces were investigated at two different doses ( $1.0 \mathrm{~g}$ for low-dose conditions and $30 \mathrm{~g}$ for high-dose conditions). In addition, subjective and quantitative assessments of the volatile compounds were conducted. 


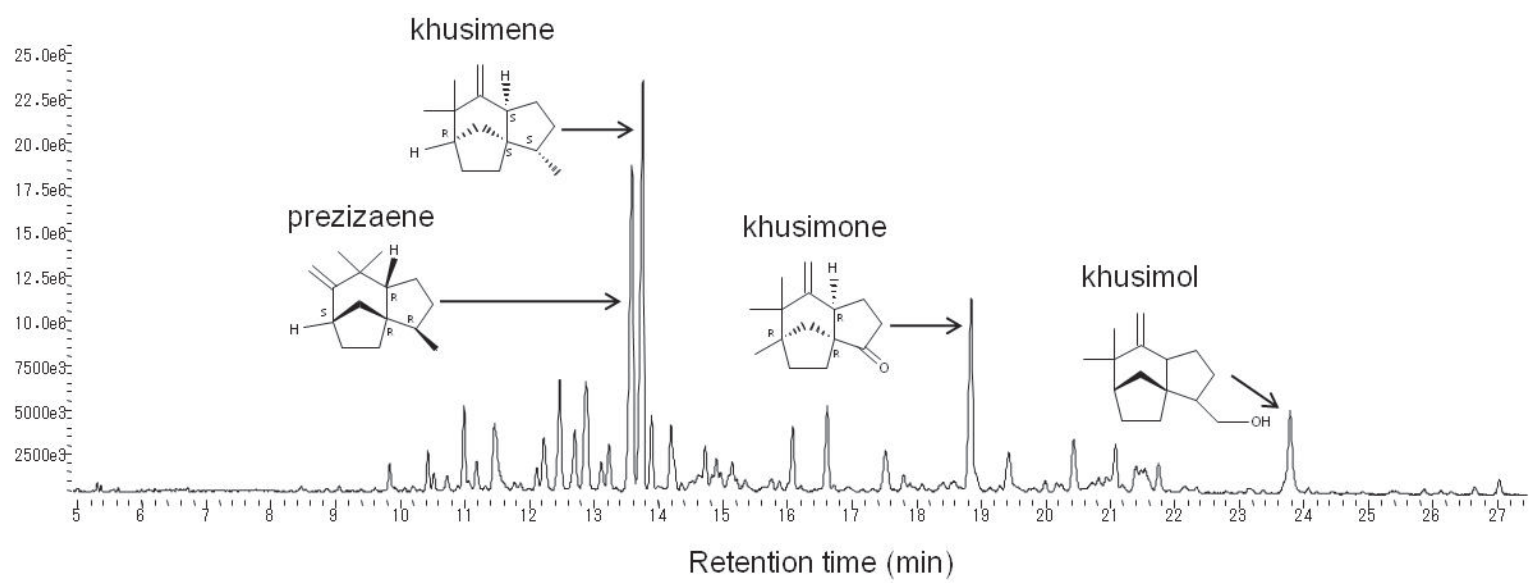

Fig. 3 Typical GC-MS chromatogram of volatile components emitted from the roots of V. zizanoides (SPME method).

\section{GC-MS analysis of volatile compounds}

Volatile components emitted from the roots of $V$. $z i$ zanoides were determined using SPME fiber adsorption in conjunction with GC-MS analysis (Fig. 3, Table 2). Seventeen compounds emitted from the roots of $V$. zizanoides were detected. Among them, prezizaene, khusimene, khusimone and khusimol were detected as dominant compounds (Fig. 3). The GC-MS analysis of the volatiles emitted from the essential oil used in our preliminary study is shown in Fig. 4.

Only eight compounds breathed by each participant during the experiment (from the baseline period to the recovery period, over $40 \mathrm{~min}$ ) were detected using a Tenax-GR and a Curie-point pyrolyzer because of the low concentration of volatile compounds: prezizaene, $0.08 \pm 0.02( \pm \mathrm{SD}) \mu \mathrm{g}$ and 0.45 $\pm 0.24 \mu \mathrm{g}$ under the low-dose conditions and the high-dose conditions, respectively: khusimene, 0.1 $\pm 0.02 \mu \mathrm{g}$ and $0.56 \pm 0.3 \mu \mathrm{g} ; \alpha$-amorphene, $0.01 \pm$ $0.01 \mu \mathrm{g}$ and $0.09 \pm 0.06 \mu \mathrm{g}$; khusimone, $0.06 \pm$ $0.02 \mu \mathrm{g}$ and $0.19 \pm 0.15 \mu \mathrm{g}$; vetiselinenol, n.d. and $0.02 \pm 0.01 \mu \mathrm{g}$; khusimol, $0.01 \pm 0.01 \mu \mathrm{g}$ and $0.08 \pm$ $0.09 \mu \mathrm{g} ; \beta$-vetivone, n.d. and $0.01 \pm 0.01 \mu \mathrm{g}$; and $\alpha$-vetivone, n.d. and $0.01 \pm 0.01 \mu \mathrm{g}$. The total amount of volatiles in the $40 \mathrm{~L}$ of air breathed during the experiment was $0.25 \pm 0.05 \mu \mathrm{g}$ under the low-dose conditions and $1.35 \pm 0.73 \mu \mathrm{g}$ under the high-dose conditions (Table 3 ).

\section{Visual discrimination task performance}

Participants performed the visual discrimination task for a 30-min working period that started 5 min after the experimental time began and ended 5 min before the experimental period ended (Table 1). The task performance was determined by the rate of true hits,
Table 2 Composition of volatiles emitted from the roots of $\mathrm{V}$. zizaninoides

\begin{tabular}{rc}
\hline No. & Components \\
\hline 1 & $\delta$-3-carene \\
2 & $n$-nonanal \\
3 & $\alpha$-copaene \\
4 & 2 -epi- $\alpha$-funebrene \\
5 & 2 -epi- $\beta$-funebrene \\
6 & $\beta$-cedrene \\
7 & prezizaene \\
8 & khusimene \\
9 & $\alpha$-amorphene \\
10 & cis-eudesma-6,11-diene \\
11 & sesquicineole \\
12 & khusimone \\
13 & vetiselinenol \\
14 & khusimol \\
15 & $E$-isovalencenol \\
16 & $\beta$-vetivone \\
17 & $\alpha$-vetivone \\
\hline
\end{tabular}

$\mathrm{p}(\mathrm{tH})$, and reaction time. The values of $\mathrm{p}(\mathrm{tH})$ and reaction time were taken as the average for each 5-min period (Fig. 5). The values of $\mathrm{p}(\mathrm{tH})$ at 20 25 min were $81.1 \pm 5.7 \%$ under the high-dose conditions and $90.2 \pm 3.6 \%$ under the control conditions; this difference was statistically significant $(P<0.05)$ (Fig. 5A). The percentage changes in the reaction time values were calculated compared with the average value between 5 and $10 \mathrm{~min}$ in the visual discrimination task. The reaction time values at 25 30 min were $105.1 \pm 2.5 \%$ under the low-dose conditions and $113.4 \pm 3.7 \%$ under the control conditions; this difference was statistically significant $(P<0.05)$ (Fig. 5B). The $\mathrm{p}(\mathrm{tH})$ values under the low-dose conditions and reaction time under the high-dose 


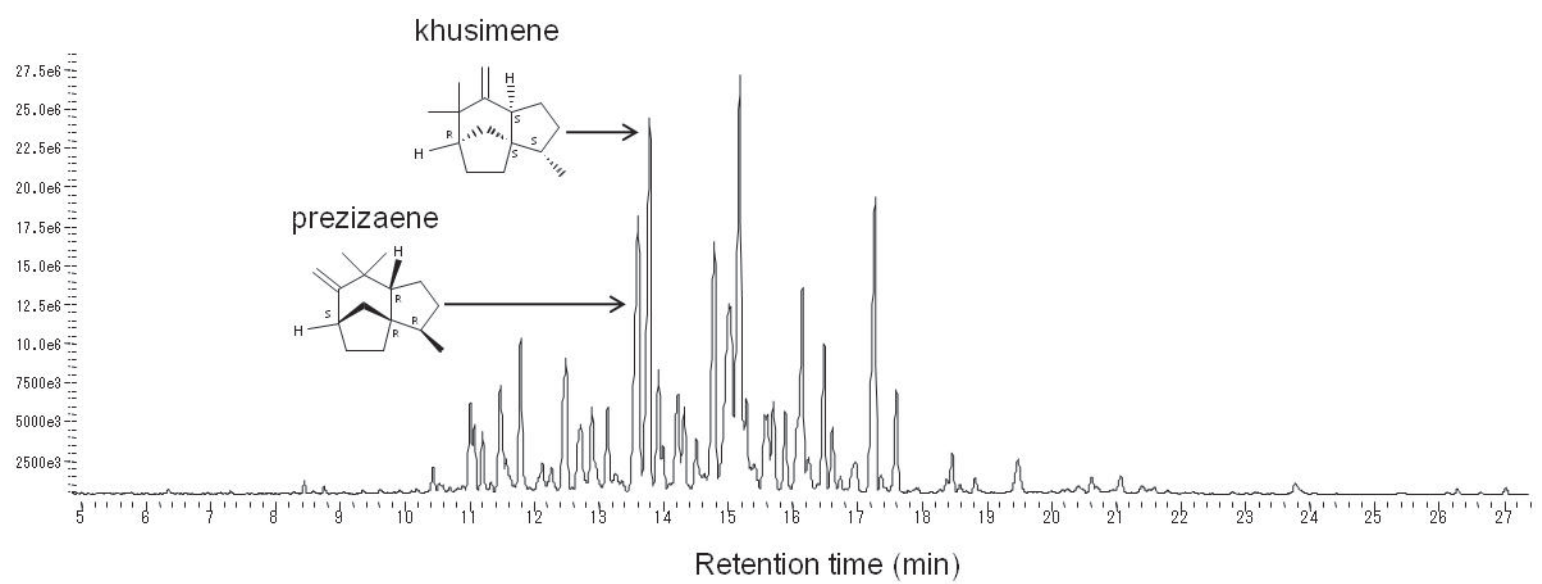

Fig. 4 Typical GC-MS chromatogram of volatile components emitted from the essential oil of $V$. zizanoides (SPME method).

Table 3 Components and contents of volatiles emitted from the roots of $V$. zizaninoides (from baseline period to recovery period, $40 \mathrm{~min}$ )

\begin{tabular}{ccc}
\hline & Low-dose & High-dose \\
\hline Components & Contents $(\mu \mathrm{g})$ & Contents $(\mu \mathrm{g})$ \\
\hline prezizaene & $0.08 \pm 0.02$ & $0.45 \pm 0.24$ \\
khusimene & $0.1 \pm 0.02$ & $0.56 \pm 0.3$ \\
$\alpha$-amorphene & $0.01 \pm 0.01$ & $0.09 \pm 0.06$ \\
khusimone & $0.06 \pm 0.02$ & $0.19 \pm 0.15$ \\
vetiselinenol & - & $0.02 \pm 0.01$ \\
khusimol & $0.01 \pm 0.01$ & $0.08 \pm 0.09$ \\
$\beta$-vetivone & - & $0.01 \pm 0.01$ \\
$\alpha$-vetivone & - & $0.01 \pm 0.01$ \\
\hline total & $0.25 \pm 0.05$ & $1.35 \pm 0.73$ \\
\hline
\end{tabular}

Data are shown as the means $\pm \mathrm{SD}(\mathrm{N}=5)$.

conditions did not show a statistically significant difference compared with the control conditions. These results showed that the volatile compounds emitted under the low-dose conditions have the potential to suppress a decline in performance, especially for reaction times in visual discrimination tasks.

\section{Analysis of $H R V$}

Statistical dispersion patterns of the R-R interval Lorenz plot showed no difference among the lowand high-dose conditions and the control conditions. The change in the values of the R-R intervals was calculated as the percentage change compared with the baseline, where no volatiles were present. The mean R-R interval values showed no statistically significant difference between the low- or high-dose conditions and the control conditions during any period (data not shown). The level of the HF components and the LF/HF ratio were defined by the average of every 5-min period. The values of HF components showed no statistically significant difference between the low- and high-dose conditions and the control conditions in any period (Fig. 6A). The values of the $\mathrm{LF} / \mathrm{HF}$ ratio at $25-30 \mathrm{~min}$ were $6.0 \pm 1.2 \%$ under the low-dose conditions and $3.7 \pm$ $1.4 \%$ under the control conditions; this difference indicated a tendency towards significance $(P<0.1)$, and average of the LF/HF ratios under the low-dose conditions was higher than that under the control conditions (Fig. 6B). These results suggest that breathing the volatile compounds emitted under low-dose conditions stimulated sympathetic nerve activity, which maintained performance during the visual discrimination task.

\section{DISCUSSION}

In this study, the results showed that breathing the volatile compounds emitted from the roots of $V$. $z i$ zanioides under low-dose conditions suppressed the decline in task performance and stimulated sympathetic nerve activity during the experiment. These findings indicate that the volatile compounds from $V$. zizanioides roots may maintain performance and sympathetic nerve system activity during a visual discrimination task. The high workloads in workspace were associated with mental health disturbance $(7,29)$. A low concentration of the volatile compounds from the roots of $V$. zizanioides could be used to reduce the negative effects of workloads during performing a visual discrimination work.

Several studies have suggested that volatile compounds emitted from aromatic herbs are useful in improving alertness while performing tasks $(10,28)$. The reaction times at 25-30 min under the low-dose conditions were shorter than those under the control 
A
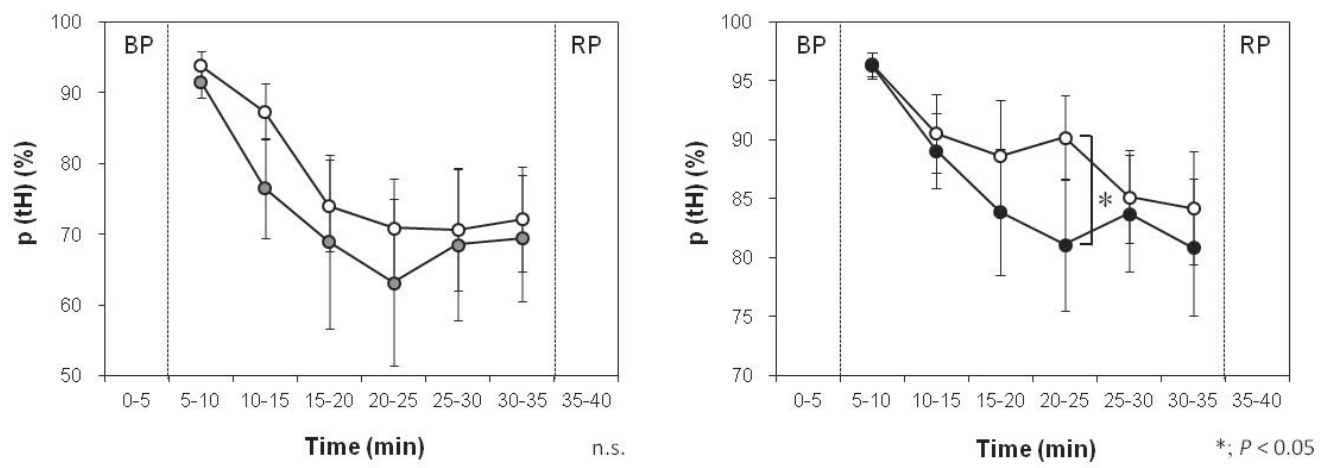

B
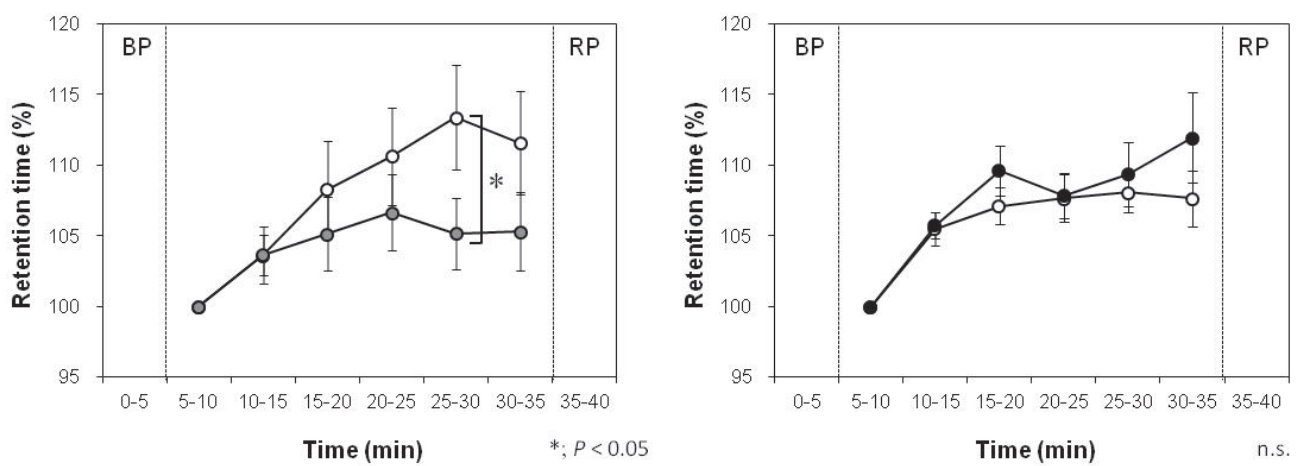

Fig. 5 Vigilance performance time course during the visual discrimination task. The program provided two indicators reflecting task performance: the rate of true hits, $\mathrm{p}(\mathrm{tH})$, defined as the rate of correct responses minus the rate of errors, and the reaction time, defined as the time taken to click when the correct targets appeared. Circles represent the average of each 5 -min period of $(A) p(t H)$ and $(B)$ reaction time under low-dose conditions (gray, $N=6$ ), high-dose conditions $($ black, $N=12$ ) and control conditions (white). Asterisks indicate statistical significance $\left({ }^{\star} P<0.05\right)$. Data are shown as the mean $\pm \mathrm{SEM}$.

conditions $(P<0.05)$ (Fig. 5B). In previous studies, a decline in performance depended on the frequency and speed of signal detection over time, and this decline usually occurs 20 to $30 \mathrm{~min}$ after task initiation, although it has been observed as early as during the first $5 \mathrm{~min}(13,24)$. Our results indicate that volatile compounds emitted under low-dose conditions can suppress the increase in reaction time during a visual discrimination task. In addition, the physiological mechanisms were probably different for the low- and high-dose conditions and the control conditions. To explain the results, we performed an additional experiment.

The autonomic nervous system, which is composed of the sympathetic and parasympathetic nervous systems, controls cardiovascular function. It has previously been reported that several aromatic herbs increase cardiovascular autonomic reactivity through changes in breathing $(9,30)$. We used the changes in the mean R-R interval, the high-frequency component (HF, $0.15-0.4 \mathrm{~Hz}$ ) and the low-frequency to high-frequency ratio (LF, $0.04-0.15 \mathrm{~Hz}$; HF, $0.15-0.4 \mathrm{~Hz}$; LF/HF ratio) of the HRV as parameters of cardiovascular function. In this study, the values of the LF/HF ratio at 25-30 min under the low-dose conditions were higher than those under the control conditions $(P<0.1)$. The averages of the $\mathrm{LF} / \mathrm{HF}$ ratios under the low-dose conditions were higher than those under the control conditions (Fig. 6B). During the task, the sympathetic nerve activity was significantly increased and the parasympathetic nerve activity decreased $(33,34)$. The results in this study taken together with results from previous studies suggest that breathing low doses of the volatile compounds from the roots of $V$. zizanioides increases sympathetic nerve activity, which 
A
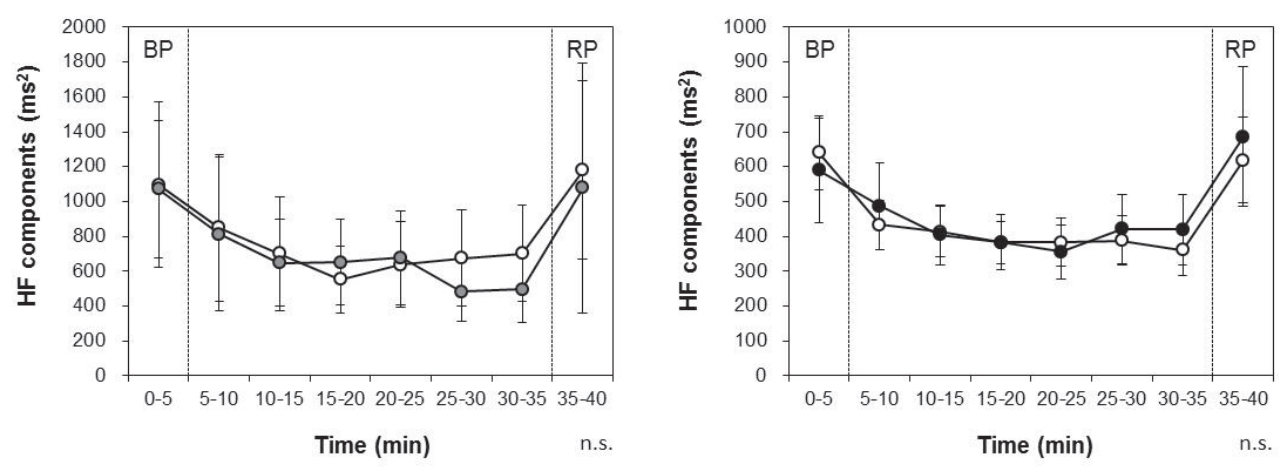

B
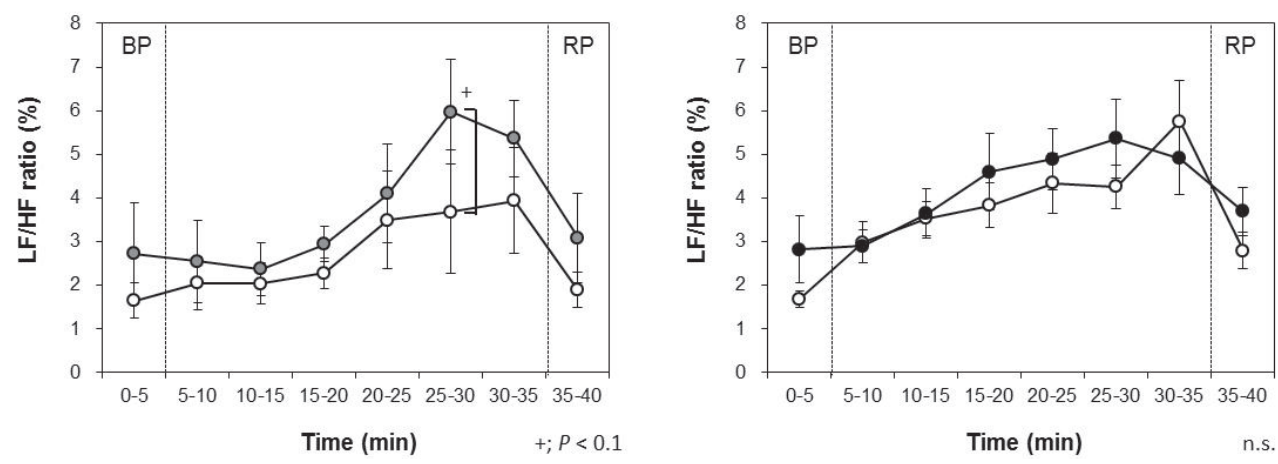

Fig. 6 Time course of HF components and LF/HF ratios in the electrocardiogram. Spectral analysis of two major components: (A) High-frequency components (HF, 0.15-0.4 Hz). (B) The ratio of low frequency to high frequency (LF/HF, 0.04$0.15 \mathrm{~Hz} / 0.15-0.4 \mathrm{~Hz}$ ). Circles represent HF components and LF/HF ratios under low-dose conditions $(\mathrm{gray}, \mathrm{N}=6), \mathrm{high}-\mathrm{dose}$ conditions (black, $\mathrm{N}=12$ ) and control conditions (white). A tendency is indicated by $+(P<0.1)$. BP, 5 -min baseline period; 30 -min working period divided into 5-min segments; RP, 5 -min recovery period. Data are shown as the mean \pm SEM.

maintains performance during the visual discrimination task.

There were also differences in the subjective assessment of the volatile compounds under high-dose and control conditions. Participants experienced a strong, heavy odor under the high-dose conditions. Pleasant and unpleasant odorants are known to provoke different degrees of vigilance; pleasant odorants have been shown to improve visual vigilance in a sustained visual discrimination task (14). This suggests that the volatile compounds emitted under low-dose conditions can maintain performance without evoking strong emotions. The essential oil of the roots of $V$. zizanioides has been reported to possess sedative properties and is traditionally used for relieving stress, anxiety, nervous tension and insomnia $(3,5)$. Blood volume in the frontal lobe of the brain was decreased by breathing the volatile compounds emitted from the essential oil of $V$. zizanioides (11); thus, the volatile compounds from $V$. zizanioides have potential sedative effects on brain activity. Our results of GC-MS analysis (Fig. 3, 4) showed that the volatile compounds emitted from the components between the roots and essential oil were different, especially from $14 \mathrm{~min}$ to $18 \mathrm{~min}$ at retention time. The compositions of these compounds were suggested to influence the subjective assessments.

The roots of $V$. zizanioides, which have a natural, fresh and reinvigorating odor, are traditionally used in Southeast Asia for household items such as mats, baskets and sachets. The present study thus provides the first experimental evidence to support the traditional use of $V$. zizanioides roots to increase focus in humans. 


\section{Acknowledgments}

We thank Mr. Kitamura for their help with data collection. The authors also appreciate the men who participated in this research. This work was supported in part by Kyushu University Interdisciplinary Programs in Education and Projects in Research Development, Kyushu University, Career Center for Women Researchers at Kyushu University, Urakami Foundation for Food and Food Culture Promotion, and the Research Grant for Young Investigators of Faculty of Agriculture, Kyushu University.

\section{REFERENCES}

1. Adams PR (2007) Identification of Essential Oil Components by Gas Chromatography/ Mass Spectrometry, $4^{\text {th }}$ edition. Allured Pub Corp, IL.

2. Arctander S (1960) Vetiver oil. In Perfume and Flavor Materials of Natural Origin. pp649-653, Allured Pub Corp, IL.

3. Bowles JE, Griffiths DM, Quirk L, Brownrigg A and Croot K (2002) Effects of essential oils and touch on resistance to nursing care procedures and other dementia-related behaviours in a residential care facility. Int J Aromat 12, 22-29.

4. Champagnat P, Figueredo G and Chalchat JC (2006) A study on the composition of commercial $V$. zizanoidesia zizanioides oils from different geographical origins. $J$ Essent Oil Res 18, 416-422.

5. Fischer-Rizzi S (1990) Vetiver. In Complete Aromatherapy Handbook: Essential Oils for Radiant Health. pp178-181, Sterling Publishing Company, NY.

6. Gould A and Martin GN (2001) 'A good odour to breathe?' The effect of plasant ambient odour on human visual vigilance. Appl Cognit Psychol 15, 225-232.

7. Haslam C, Atkinson S, Brown SS and Haslam RA (2005) Anxiety and depression in the workplace: effects on the individual and organization. $J$ Affect Disord 88, 209-215.

8. Hammer KA, Carson CF and Riley TV (1999) Antimicrobial activity of essential oils and other plant extracts. $J$ Appl Microbiol 86, 985-990.

9. Haze S, Sakai K and Gozu Y (2002) Effects of fragrance inhalation on sympathetic activity in normal adults. Jpn $J$ Pharmacol 90, 247-253.

10. Heuberger E and Imberger J (2010) The influence of essential oils on human vigilance. Nat Prod Commun 5, 14411446.

11. Itano I, Shimizu S, Yuka A, Tanabe T, Sorai Y, Nakagawa A and Takebayashi N (2006) The preliminary study about effects of essential oils by near infrared spectroscopy; The relations between fragrance and stress with blood volume in the frontal lobe of brain. Aroma Res 28, 54-59.

12. Jellinek JS (1997) Psychodynamic odor effects and their mechanisms. Perfum Flavor 22, 29-41.

13. Jerison HJ and Pickett RM (1963) Vigilance: a review and re-evaluation. Hum Factors 5, 211-238.

14. Jones KS, Ruhl RL, Warm JS and Dember WN (1999) Olfaction and vigilance: the role of hedonic value. In Automation Technology and Human Performance: Current Research and Trends (Scerbo MW, Mouloua M, eds), pp193-197, Mahwah, NJ.

15. Kim HJ, Chen F, Wang X, Chung HY and Jin Z (2005)
Evaluation of antioxidant activity of $V$. zizanoides ( $V$. zizanoidesia zizanioides L.) oil and identification of its antioxidant constituents. J Agric Food Chem 53, 7691-7695.

16. Kraft P, Bajgrowicz JA, Denis C and Fráter G (2000) Odds and trends: recent development in the chemistry of volatiles. Angew Chem Int Ed 39, 2980-3010.

17. Maffei M (2002) Introduction to the genus Vetiveria. In The Genus V. zizanoidesia, pp1-18, Taylor \& Francis, London and NY.

18. Maistrello L, Henderson G and Laine R (2001) Efficacy of $V$. zizanoides oil and nootkatone as soil barriers against Formosan subterranean termite (Isoptera: Rhinotermitidae). J Econ Entomol 94, 1532-1537.

19. Matsubara E, Fukagawa M, Ishiji Y, Hatayama T, Kitamura S, Kawabe T, Okamoto T, Ohnuki K, Shimizu K and Kondo R (2009) Evaluation system for the effects of odors on sustained attention. Aroma Res 39, 211-216.

20. Matsubara E, Fukagawa M, Okamoto T, Fukuda A, Hayashi C, Ohnuki K, Shimizu K and Kondo R (2011) Volatiles emitted from the leaves of Laurus nobilis L., improve vigilance performance in visual discrimination task. Biomed Res 32, 1928.

21. Matsubara E, Fukagawa M,Okamoto T, Ohnuki K, Shimizu $\mathrm{K}$ and Kondo R (2011) The essential oil of Abies sibirica (Pinaceae) reduces arousal levels after visual display terminal work. Flav Fragr J 26, 204-210.

22. Matsubara E, Fukagawa M, Okamoto T, Ohnuki K, Shimizu $\mathrm{K}$ and Kondo R (2011) (-)-Bornyl acetate induces autonomic relaxation and reduces arousal level after visual display terminal work without any influences of task performance in low-dose condition. Biomed Res 32, 151-157.

23. Martinez J, Rosa, PT, Menut C, Leydet A, Brat P, Pallet D and Meireles MA (2004) Valorization of Brazilian V. zizanoides ( $V$. zizanoidesia zizanioides L. Nahs ex Samll) oil. $J$ Agric Food Chem 52, 6578-6584.

24. Nuechterlein KH, Parasuraman R and Jiang Q (1983) Visual sustained attention: image degradation produces rapid sensitivity decrement over time. Science 110, 327-329.

25. Peyron L (1989) V. zizanoides in perfumery. Quintessenza 13, 4-14.

26. Pripdeevech P, Wongpornchai S and Promsiri A (2006) Highly volatile constituents of Vetiveria zizanioides roots grown under different cultivation conditions. Molecules 11, 817 826.

27. Shepherd GM (2006) Smell images and the flavour system in the human brain. Nature, 444, 316-321.

28. Shimizu K, Gyokusen M, Kitamura S, Kawabe T, Kozaki T, Ishibashi K, Izumi R, Mizunoya W, Ohnuki K and Kondo R (2008) Essential oil of lavender inhibited the decreased attention during a long-term task in humans. Biosci Biotechnol Biochem 72, 1944-1947.

29. Takanishi T, Ebara T, Murasaki G, Kubo T, Tachi N, Itani T and Kamijima M (2010) Interactive model of subsidiary behaviors, work performance and atonomic nerve activity during visual display terminal work. $J$ Occup Health 52, 39-47.

30. Tanida M, Niijima A, Shen J, Nakamura T and Nagai K (2005) Olfactory stimulation with scent of essential ol of grapefruit affects autonomic neurotransmission and blood pressure. Brain Res 1058, 44-55.

31. Task Force of the European Society of Cardiology and the North American Society of Pacing Electrophysiology (1996) Heart rate variability standard of measurement, physiological interpretation, and clinical use. Circulation 93, 1043-1065.

32. Warm JS, Dember WN and Parasuraman R (1991) Effects of 
olfactory stimulation on performance and stress in a visual sustained attention task. J Soc Cosmet Chem 42, 199-210.

33. Xu Z, Hilton HJ, Gates GJ, Jelic S, Stern Y, Bartels MN, Demeersman RE and Basner RC (2005) Increased sympathetic and decreased parasympathetic cardiovascular modulation in normal humans with acute sleep deprivation. $J$ Appl Physiol 98, 2024-2032.

34. Yu X, Zhang J, Xie D,Wang J and Zhang C (2009) Relation- ship between scalp potential and autonomic nervous activity during a mental arithmetic task. Auton Neurosci: Basic Clin 146, 81-86.

35. Zhu BCR, Henderson G, Chen F, Fei H and Laine RA (2001) Evaluation of $V$. zizanoides oil and seven insect-active essential oils against the Formosan subterranean termite. $J$ Chem Ecol 27, 1617-1625. 